\title{
Demographics, Pain Characteristics and Diagnostic Classification Profile of Chronic Non-Cancer Pain Patients Attending a Canadian University-Affiliated Community Pain Clinic
}

\author{
S. Fatima Lakha (D) - Amol Deshpande - Demetry Assimakopoulos • \\ Angela Mailis
}

Received: June 8, 2021 / Accepted: August 4, 2021 / Published online: August 19, 2021

(c) The Author(s) 2021

\section{ABSTRACT}

Introduction: Little information exists regarding the characteristics of patients with chronic non-cancer pain (CNCP) attending Canadian pain clinics. The study describes the demographics, pain characteristics and the diagnostic classification profile of such patients attending

S. F. Lakha · D. Assimakopoulos · A. Mailis Pain and Wellness Centre, Vaughan, ON, Canada

S. F. Lakha $(\bowtie) \cdot$ A. Mailis

2301 Major Mackenzie Drive West Unit 101,

Vaughan, ON L6A 3Z3, Canada

e-mail: sfatima.lakha@utoronto.ca

S. F. Lakha · A. Mailis

Institute of Medical Sciences, University of Toronto, Toronto, ON, Canada

\section{A. Deshpande}

Department of Family and Community Medicine, Toronto Rehabilitation Institute, UHN, Quality and Innovation, University of Toronto, Toronto, ON, Canada

e-mail: amol.deshpande@uhn.ca

\section{Assimakopoulos}

Chiropractor, University Health Network, Comprehensive Integrated Pain Program Rehabilitation Pain Service, Toronto, ON, Canada e-mail: demetry@thepwc.ca

\section{A. Mailis}

Division of Physical Medicine and Rehabilitation, Department of Medicine, University of Toronto, Toronto, ON, Canada

e-mail: angela.mailis@thepwc.ca a university-affiliated community-based pain clinic in the Greater Toronto Area.

Methods: Retrospective descriptive study based on 644 unique consecutive CNCP patients assessed between January 2016 and December 2017.

Results: The female/male ratio was $1.6: 1 ; 80 \%$ were younger than 65 years; $43 \%$ held some form of employment (full-time, part-time or self employment); median pain duration was 3 years; car accidents and medical conditions accounted for 28 and $27 \%$ of pain onset, respectively; $34 \%$ had four or more distinct areas of pain; and low back pain (LBP) was the most prevalent site $(66 \%)$, but was the sole site of pain in less than a third of these patients. Age was positively associated with LBP prevalence. Self-reported health service utilization (visits to the emergency room, pain physician or psychologist) increased with patient psychopathology. Cannabis was used by $15 \%$ of the cohort and opioids by $34.5 \%$, with only one in six opioid users exceeding $90 \mathrm{mg}$ of morphine equivalent dose per day. Comparison of our data to three previously published studies from other Canadian pain clinics demonstrated both similarities and substantial differences between the populations.

Conclusion: Our study highlights regional differences between CNCP population phenotypes. Recognition of biomedical, psychological and socio-environmental factors affecting pain should be considered for patient stratification 
and rational approaches to treatment, as "one size treatment does not fit all".

Keywords: Chronic pain patients; Demographics; Community-based practice

\section{Key Summary Points}

Our study demonstrates that chronic pain patient populations present with various characteristics that can be assessed and identified in clinical practice settings through systematic clinical encounters.

Grouping of patients takes into account biomedical, psychological and socioenvironmental factors differentially affecting perception and expression of pain.

Recognition of distinct pain patient groups and other features can lead to rational therapeutic interventions, improved outcomes and reduced health care and disability costs.

\section{INTRODUCTION}

Chronic non-cancer pain (CNCP) is defined as pain that lasts longer than 3-6 months, or beyond the duration required for normal tissue healing after an acutely painful event [1]. Chronic pain results from combined biological, psychological and social factors, and most often requires a multifactorial approach to evaluation and management [2]. One in five Canadians lives with chronic pain [3-5]. Public health care costs for the management of chronic pain have been estimated at $\$ 7.2$ billion annually across Canada [6], while the full economic impact related to chronic pain (public and private costs, disability costs, loss of productivity, etc.) in Canada has reached \$56-60 billion annually [7].

When access is available, Canadian CNCP patients are treated in a number of clinical settings by a variety of disparate health professionals including primary care, secondary care, allied health care and dedicated pain specialists, with medical care costs and costs of interventional procedures covered by the national health care system. Allied health care costs (psychological services, physiotherapy, chiropractic, etc.), however, are paid by Extended Health Benefits/private insurance or out of pocket. There are a number of varied treatment options, reflecting heterogeneity among patients, practitioner training and philosophy, financial considerations, distance, availability of treatments and geographic differences.

Currently, there is little information regarding the demographics and pain characteristics of patients attending Canadian pain clinics. The studies that do exist describe populations in a tertiary-care hospital-based pain clinic in Toronto, Ontario [8-10], the Quebec Pain Registry [11] and a community-based clinic in Vancouver, Canada [12].

The primary aim of the present study is to describe the demographics, pain characteristics and diagnostic classification profile of $\mathrm{CNCP}$ patients referred for pain consultation to the Pain and Wellness Centre (PWC), a universityaffiliated community-based non-interventional pain clinic in the city of Vaughan (north of Toronto) in the Greater Toronto Area (GTA). GTA encompasses an area of $7124 \mathrm{~km}^{2}$ with a population of 5.93 million. A detailed description of the PWC model of care was recently published [13]. The secondary aim is to compare our findings to those of existing studies from Canadian pain clinics to determine similarities and differences among the populations.

\section{METHODS}

This is a retrospective descriptive pragmatic, practice-based study of 644 consecutive CNCP patients referred to the PWC over 24 months (January 2016-December 2017). The study was approved by the University of Toronto Research Ethics Board (Protocol\# 36903). Informed consent was obtained from all the patients attending the pain program (outlining the use of their 
data anonymously in aggregate format for research purposes).

\section{Data Collection}

We gathered data on demographics including age, sex, marital status, work status, country of birth and education, and pain characteristics including pain site(s), average pain ratings on the Brief Pain Inventory (BPI), BPI interference score (maximum 70; the higher the score, the greater the pain interference and disability) and pain duration, extracted from patients via standard intake questionnaires at the time of first consultation. "Place or country of birth" was used as an identifier, and patients were classified as Canadian-born (CB) or foreign-born (FB).

Diagnoses were extracted from chart review (original consultation, review of referral records, as well as, when needed, additional reports and findings from investigations collected during follow-up appointments). Specific coding of different pain mechanisms, i.e., neuropathic pain (NP) disorders (including neuropathies, radiculopathies, spinal cord and brain conditions such as stroke and spinal cord injury), nociceptive pain (NC) disorders (including musculoskeletal [MSK] disorders such as osteoarthritis, fractures and soft tissue injuries, and nociceptive visceral pain such as pancreatitis) and mixed conditions (neuropathic and nociceptive pain disorder), was obtained based on a detailed list of multiple biomedical disorders established in our data compilation.

All patients were referred to the centre by their primary care physicians or specialists and underwent an extensive evaluation by at least two pain team members (a physician and a chiropractor), including a detailed history regarding presenting pain complaints, past medical, surgical, psychiatric and psychosocial history, and review of present and past medications, treatments, and all pertinent imaging and laboratory investigations (routine evaluations in our centre). This was followed by a thorough physical examination and, if needed, additional investigations. Additionally, all patients completed validated batteries including the Brief Pain Inventory (BPI), the Patient Health Questionnaire (PHQ-9) and the Generalized Anxiety Disorder Questionnaire (GAD-7) to further assist the evaluating team in understanding pain interference and psychoemotional disturbance. In particular, psychoemotional factors were deduced from (1) information obtained during history taking, (2) behavioural observations, (3) response to validated batteries, (4) review of previous psychological/psychiatric reports if available, and (5) information in the referring physician's files. Subsequently, for this study, patients were grouped into one of three diagnostic categories based on underlying biomedical conditions, psycho-emotional/psychosocial factors, or a combination of both, as follows: group I patients had significant biomedical condition(s) accounting for pain and disability without excessive psychological influence (based on present clinical diagnostic means available such as clinical examination findings combined with diagnostic imaging studies, electromyography and nerve conduction studies, surgical findings, etc.). Group II patients had detectable biomedical pathology, but additional psychological factors were deemed to play a significant role in their perceived disability and presentation. Group III patients either lacked detectable biomedical pathology or had minimal and inconsequential pathology (such as localized minor soft tissue tenderness) in the presence of high levels of disability and pain severity, while psychological and psychosocial factors were considered fundamental in their presentation. A group III diagnosis was not a diagnosis of exclusion, i.e., made solely on the basis of lack of biomedical pathology. Rather, such a diagnosis required detailed clinical information obtained by history, physical examination and review of files, combined with behavioural observations, and in the absence of positive investigations or findings. The above diagnostic classification has been widely used and described in detail in previous publications from our group [8-10, 14-16].

We collected data on opioid consumption at the time of entry to the PWC and categorized patients as non-opioid users, low-opioid users (daily morphine equivalent dosage (MED) 
of $\leq 90 \mathrm{mg}$ ) or high-opioid users (daily MED > $90 \mathrm{mg}$ ) (based on the 2017 Canadian Guideline on opioid prescribing) [17]. Data were also gathered on current cannabis use.

\section{Statistical Analysis}

All data were analysed using SPSS (Statistical Package for the Social Sciences v.16.0, SPSS Inc., Chicago, IL, USA). Descriptive statistics were used for demographics, pain, diagnostic groups and opioid data. The descriptive analysis consisted of means and proportions according to the nature of the variables. As a dispersion measurement, the standard deviations were calculated. For categorical data, proportion and size of each category for all demographic characteristics (such as sex, marital status, education, work status and country of birth), body map areas and opioid use were calculated. Means and standard deviation were computed as well for pain characteristics (such as pain rating, interferences score, pain duration) and opioid dosages. For statistical comparison of categorical variables, the Pearson $\chi^{2}$ test or Fisher's exact tests were used. For continuous variables, a $t$-test was used for comparisons between two groups, and analysis of variance was used to determine the association between more than two groups. Bonferroni correction was used to compare significant differences between means within a group; $\chi^{2}$ goodness-offit test was used for the ratio analysis. At a 95\% confidence interval, a two-sided $p$ value of $<$ 0.05 was used to define minimal statistical significance. When the denominator is different due to missing data, the exact number will be indicated in brackets.

\section{RESULTS}

General demographic data are presented in Table 1. Notably, women outnumbered men in the study (female: male ratio 1.6:1). Eighty percent of patients were younger than 65 years of age. Sixty percent of patients had obtained higher education (college, university or postgraduate studies). Forty-three percent of the population held some type of employment (full-time, part-time or self-employed), while $17 \%$ were retirees and $34 \%$ were unable to work or were disabled. More than one half of patients $(57 \%)$ were Canadian-born (CB), while foreignborn (FB) patients were older and less educated and had a greater proportion of retirees (26\%).

Prior to attending the PWC, based on selfreports over the previous 2 years, $16 \%$ of the patients had visited emergency departments and $12 \%$ had seen a pain physician. Visits to several allied health professionals paid by extended health benefits, car insurance, or out of pocket occurred with the following frequency: physiotherapist (49\%), massage therapist (36\%), chiropractor (35\%), psychologist (15\%) and naturopathic doctor (6\%).

\section{Duration, Severity and Factors Associated with Onset of Pain Problem}

The average duration of pain at the time of presentation to the PWC was 7 years, with a range of 3 months to 70 years. The median duration of pain was 3 years. Motor vehicle accidents and medical conditions (e.g., diabetic neuropathy, migraines, multiple sclerosis, osteoporosis-related fractures, degenerative joint disease, disc herniation, spinal stenosis) were associated with pain onset in $28 \%$ and $27 \%$ of the patients, respectively. While spontaneous onset of pain (i.e., without an inciting event) was reported in $20 \%$ of the entire population, this level was much higher for females compared to males $(27 \%$ vs $11 \%)(p<0.05)$. More than half of patients (59\%) had severe pain (> 7/10 BPI average pain), while the average BPI pain interference score was high (49 \pm 15 , range $4-70)$. Details are presented in Table 2 .

\section{Diagnostic Categorization}

Data for diagnostic classification were available for 628 of the 644 patients. Sixteen patients required more investigations to determine diagnosis; therefore, we excluded them from the analysis. Less than half of the population (41\%, $n=261$; group I) had a primarily biomedical cause for their pain, i.e., specific 
Table 1 Demographic characteristics of population as a whole and by sex

\begin{tabular}{|c|c|c|c|}
\hline & $\begin{array}{l}\text { All PWC population } \\
N=644\end{array}$ & $\begin{array}{l}\text { Females } \\
N=398\end{array}$ & $\begin{array}{l}\text { Males } \\
N=246\end{array}$ \\
\hline \multicolumn{4}{|l|}{ Demographic variables } \\
\hline $\operatorname{Sex}(N=644)$ & $n(\%)$ & $n(\%)$ & $n(\%)$ \\
\hline (a) Male & $246(38)^{\mathrm{a}}$ & & \\
\hline (b) Female & $398(62)$ & & \\
\hline Age (mean \pm std) (range) & $\begin{array}{l}50.4 \pm 16.03 \\
\quad(18-92 \text { years })\end{array}$ & $\begin{array}{l}50 \pm 15 \\
\quad(18-87 \text { years })\end{array}$ & $\begin{array}{l}51 \pm 17 \\
\quad(18-92 \text { years })\end{array}$ \\
\hline Age categories $(N=644)$ & & $N=398$ & $N=246$ \\
\hline $18-25$ years & $39(6)^{\mathrm{a}}$ & $23(6)$ & $16(7)$ \\
\hline $26-35$ years & $93(14)$ & $54(14)$ & $39(16)$ \\
\hline $36-45$ years & $106(16)$ & $69(17)$ & $37(15)$ \\
\hline $46-55$ years & $167(26)$ & $112(28)$ & $55(22)$ \\
\hline $56-64$ years & $113(18)$ & $68(17)$ & $45(18)$ \\
\hline$>65$ & $126(20)$ & $72(18)$ & $54(22)$ \\
\hline$<65(\%)(\mathrm{F} / \mathrm{M}=1.7 / 1)$ & $518(80)^{\mathrm{a}}$ & $326(82)^{\mathrm{a}}$ & $192(78)^{\mathrm{a}}$ \\
\hline$\geq 65(\%)(\mathrm{F} / \mathrm{M}=1.3 / 1)$ & $126(20)$ & $72(18)$ & $54(22)$ \\
\hline Place of birth & $N=643$ & $N=398$ & $N=245$ \\
\hline Canadian-born & $364(57)^{\mathrm{a}}$ & $232(58)$ & $132(54)$ \\
\hline Foreign-born & $279(43)$ & $166(42)$ & $113(46)$ \\
\hline Marital status & $N=637$ & $N=392$ & $N=245$ \\
\hline (a) Single & $134(22)$ & $74(19)^{\mathrm{a}}$ & $6(24)$ \\
\hline (b) Divorced & $6(9)$ & $44(11)$ & $16(7)$ \\
\hline (c) Widow & $34(5)$ & $24(6)$ & $10(4)$ \\
\hline (d) Common law & $24(4)$ & $16(4)$ & $8(3)$ \\
\hline (e) Married & $374(59)^{\mathrm{a}}$ & $226(58)$ & $148(60)$ \\
\hline (f) Separated & $11(2)$ & $8(2)$ & $3(1)$ \\
\hline Level of education & $N=608$ & $N=373$ & $N=235$ \\
\hline (a) Elementary school/grade school or less & $54(9)$ & $25(7)$ & $29(12)$ \\
\hline (b) High school & $173(8)$ & $98(26)$ & $75(32)$ \\
\hline (c) College & $225(37)$ & $147(39)$ & $78(33)$ \\
\hline (d) University & $84(14)$ & $61(16)$ & $23(10)$ \\
\hline (e) Post graduate & $57(9)$ & $37(10)$ & $20(9)$ \\
\hline (f) Trade school & $15(2)^{\mathrm{a}}$ & $5(1)$ & $10(4)$ \\
\hline
\end{tabular}


Table 1 continued

\begin{tabular}{llll}
\hline & $\begin{array}{l}\text { All PWC } \\
\text { population } N=\mathbf{6 4 4}\end{array}$ & Females $N=\mathbf{3 9 8}$ & Males $N=\mathbf{2 4 6}$ \\
\hline Work status & $N=632$ & $N=386$ & $N=246$ \\
(a) Full-time work & $175(28)$ & $102(26)$ & $73(30)$ \\
(b) Part-time work & $40(6)$ & $32(8)$ & $8(3)$ \\
(c) Unable to work & $217(34)$ & $129(33)$ & $88(36)$ \\
(d) Retired (not working) & $108(17)$ & $62(16)$ & $46(19)$ \\
(e) Self-employed & $56(9)$ & $29(6)$ & $27(11)$ \\
(f) Others & $36(6)$ & $32(8)$ & $4(2)$ \\
Extended health benefits & & $146(37)$ & $79(32)^{\mathrm{a}}$ \\
(a) Yes & $225(35)^{\mathrm{a}}$ & $252(63)$ & $167(68)$ \\
(b) No & $419(65)$ & & $36(15)$ \\
In past 2 years, visits to health professionals & $(644)$ & $69(17)$ & $120(49)$ \\
(a) Emergency & $105(16)$ & $196(49)$ & $80(33)$ \\
(b) Physiotherapist & $316(49)$ & $146(37)$ & $14(5)$ \\
(c) Chiropractor & $226(35)$ & $23(6)$ & $70(32)$ \\
(d) Naturopathic doctor & $37(6)$ & $164(47)$ & $38(15)$ \\
(e) Massage therapist & $234(36)$ & $58(15)$ & $32(13)$ \\
(f) Psychologist & $96(15)$ & $42(11)$ & \\
(g) Pain doctor & $74(12)$ & & \\
\hline
\end{tabular}

${ }^{a}$ Denotes statistical significance among the categories

disease or structural lesion(s) as result of injury or surgery; $43 \%$ had mixed biomedical and psychological/psychosocial pathology $(n=267$; group II); and 16\% ( $n=100$; group III $)$ had predominant psychopathology (mood and/or anxiety disorder or other psychiatric disorder untreated or poorly treated) with no substantial detectable medical pathology.

Spontaneous onset of pain was reported in half of group I patients (51\%), as compared to $14 \%$ for group II and $2 \%$ for group III. On the other hand, motor vehicle accidents were cited as the leading cause of chronic pain in groups II and III ( $42 \%$ and $41 \%$, respectively), while they rarely accounted for the onset of pain in group I $(10 \%)(p<0.01)$.
Pain generators and specific mechanisms were determined for groups I and II $(n=528)$, as they were considered primary or significant contributors to their pain complaints. Nociceptive conditions were documented in $62 \%$ $(n=326)$, mixed nociceptive and neuropathic pain in $34 \%(n=178)$, and isolated neuropathic conditions in $5 \%(n=24)$. Males in general were more likely to have detectable biomedical pathology than females ( $53 \%$ vs $34 \%, p<0.05$ ).

Statistically significant age differences existed for the three diagnostic pain groups $(F=19$, $p<0.0001$ ): group I patients were older (mean age $56 \pm 17$ years) than group II (mean age $47 \pm 14$ years) or group III (mean age $46 \pm 14$ years). 
Table 2 Pain characteristics of population as a whole and by sex

\begin{tabular}{|c|c|c|c|}
\hline & $\begin{array}{l}\text { All PWC population } \\
N=644(\%)\end{array}$ & $\begin{array}{l}\text { Females } \\
N=398\end{array}$ & $\begin{array}{l}\text { Males } \\
N=246\end{array}$ \\
\hline Pain characteristics & $n(\%)$ & $n(\%)$ & $n(\%)$ \\
\hline \multicolumn{4}{|l|}{ Pain cause $(N=641)$} \\
\hline Disease & $174(27)^{\mathrm{a}}$ & $92(23)^{\mathrm{a}}$ & $82(34)^{\mathrm{a}}$ \\
\hline Spontaneous & $132(20)$ & $106(27)$ & $26(11)^{\mathrm{a}}$ \\
\hline Trauma & $302(47)$ & $176(44)$ & $126(51)$ \\
\hline -MVA & $180(28)$ & $108(27)$ & $72(29)$ \\
\hline -Work-related accident & $41(6)$ & $17(4)$ & $24(10)^{\mathrm{a}}$ \\
\hline -Sport injury & $22(3)$ & $10(3)$ & $12(5)$ \\
\hline -Slip and fall & $29(5)$ & $20(5)$ & $9(4)$ \\
\hline -Surgery & $15(2)$ & $10(3)$ & $5(2)$ \\
\hline -Other trauma & $15(2)$ & $11(3)$ & $4(2)$ \\
\hline$>1$ cause & $33(5)$ & $22(6)$ & $11(5)$ \\
\hline \multicolumn{4}{|l|}{ BPI scale pain ratings } \\
\hline $\begin{array}{l}\text { Pain right now (current), }(N=633) \\
\text { (mean } \pm \text { std) }\end{array}$ & $6.3 \pm 2.3$ & $6.5 \pm 2.3$ & $6.1 \pm 2.4$ \\
\hline Pain on average $(N=617)($ mean \pm std $)$ & $7 \pm 2$ & $7 \pm 2$ & $6.4 \pm 2$ \\
\hline Pain severity & $N=617$ & $N=380$ & $N=237$ \\
\hline Mild & $224(36)$ & $16(4)$ & $15(6)$ \\
\hline Moderate & $31(5)$ & $127(33)$ & $97(41)^{\mathrm{a}}$ \\
\hline Severe & $362(59)^{\mathrm{a}}$ & $237(63)$ & $125(53)^{\mathrm{a}}$ \\
\hline \multicolumn{4}{|c|}{ Cumulative score of pain interference $(N=636)$} \\
\hline$($ mean \pm std $)$ & $49 \pm 15$ & $49 \pm 14$ & $48 \pm 15$ \\
\hline (range) & $(4-70)$ & $(4-70)$ & $(5-70)$ \\
\hline \multicolumn{4}{|l|}{ Duration of pain (months) } \\
\hline Mean \pm std & $\begin{array}{l}87.8(7.3 \\
\text { years }) \pm 122\end{array}$ & $\begin{array}{l}82(6.8 \\
\text { years }) \pm 109\end{array}$ & $\begin{array}{l}98(8.2 \\
\text { years }) \pm 139^{\mathrm{a}}\end{array}$ \\
\hline Median & 36 months & 36 months & 38 months \\
\hline Range & (3 months -70 years) & ( 3 months -50 years) & ( 3 months -70 years) \\
\hline
\end{tabular}

$M V A$ motor vehicle accident

${ }^{a}$ Denotes statistical significance among the categories

Self-reported health service utilization over the previous 2 years for groups I, II and III, respectively, increased in relation to patient psychopathology, as demonstrated by visits to the emergency room (ER; 12\%, 18\%, 22\%), pain physician $(7 \%, 12 \%, 19 \%)$ or psychologist $(5 \%$, 
19\%, 74\%). Similarly, the proportion of patients with severe pain increased in tandem with the presence of psychopathology (Fig. 1) with more than three fourths $(81 \%)$ of group III patients reporting severe pain. Additional data are shown in Table 2.

\section{Pain Sites}

Low back pain (LBP), with or without leg pain, was the most common site of pain, reported in $66 \%$ of patients. However, low back pain as the only pain complaint was present only in $16 \%$ of the total population (13\% in females and $20 \%$ in males, $p<0.5$ ). Single-site pain (other than low back) was present in 14\% of the cohort, and multisite pain (four or more sites, including chronic widespread pain, or CWP) in $34 \%$ of the whole population (present in $28 \%$ of males and $38 \%$ of females; $p<0.05$ ). Data are shown in Table 3.

We found several age-related differences relating to number of pain sites. Single-site LBP, non-single-site LBP, and multisite pain were statistically different between the younger $(<65)$ and the older $(>65)$ groups, as follows: $13 \%$ vs $25 \%$; $53 \%$ vs $37 \%$; and $37 \%$ vs $21 \%$, respectively (see Table 3 ).

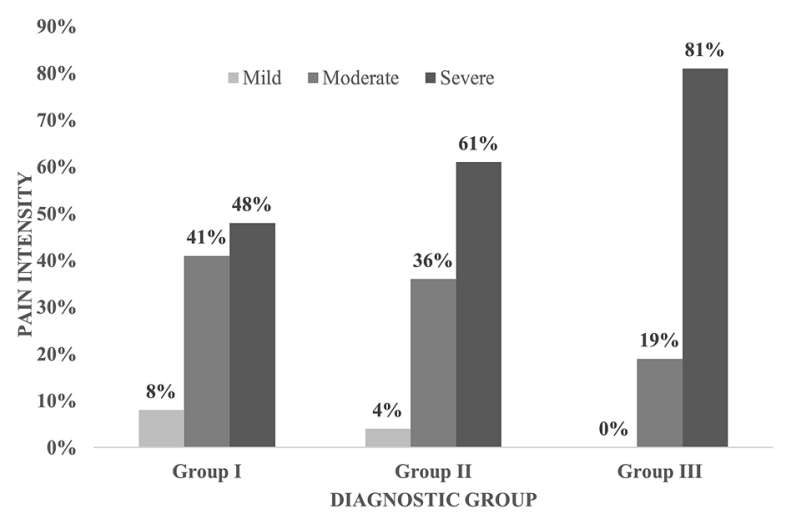

Fig. 1 Diagnostic group vs pain intensity. The percentage of patients with severe pain increased with the presence of psychopathology with more of group III patients reporting severe pain $(p<0.05)$

\section{Chronic Widespread Pain and Non- Anatomical Sensory Abnormalities}

CWP was found in $11 \%$ of the entire cohort $(N=72 / 628)$, but was specifically confined to groups II and III (12\% in group II and 35\% in group III). Additionally, $10 \%$ of all patients (60/ 628) had pain together with sensory abnormalities, involving usually half of the body, not consistent with peripheral nerve, root or dermatomal distributions (decreased sensation in $87 \%$ and increased sensation in $13 \%$ of the patients in this specific subgroup). Only a minority of CWP patients (18\%) had such sensory abnormalities confined in the worst site of pain. The prevalence of both CWP and sensory abnormalities in the age group younger than 65 years of age was twice that compared to the over-65 group (CWP 12\% vs 6\% and sensory abnormalities $8 \%$ vs 3\%, respectively).

In terms of sex, CWP was present in $15 \%$ of females and $5 \%$ of males in the entire cohort $(\mathrm{F} /$ $\mathrm{M} 3 / 1), 17 \%$ of females and $4 \%$ of the males in group II (F/M 4/1) and 41\% of females and 30\% of the males in group III (F/M 1.4/1).

In terms of employment for patients with CWP or sensory abnormalities, $43 \%$ of CWP patients and $46 \%$ of those with sensory abnormalities in group II, held some form of employment (full-time, part-time or self-employed). In group III, employment dropped to half for both the CWP patients (21\%) and those with pure sensory deficits or gains (25\%).

\section{Opioid and Cannabis Use}

Opioids were used by $222 / 644$ patients (34.5\%). Mean dose and range were calculated only for patients who were taking regular preparations that could be converted to morphine equivalents $(N=162)$. A minority of patients consumed tramadol preparations (alone or in combination with other opioids, $n=15$ ), tapentadol $(n=3)$ and buprenorphine (Butrans patch, $n=1)$, while seven patients were on methadone alone or in combination with other opioids (mean methadone $76 \mathrm{mg}$; range $50-170 \mathrm{mg})$. Only $17 \%$ of opioid users $(N=28)$ exceeded $90 \mathrm{mg}$ of morphine equivalent dose 
Table 3 Body map sites of population as a whole and by sex and age

\begin{tabular}{|c|c|c|c|c|c|}
\hline Body map sites & $\begin{array}{l}\text { All } \\
N=644 \\
\quad(\%)\end{array}$ & $\begin{array}{c}\text { Females } \\
N=398 \\
(\%)\end{array}$ & $\begin{array}{l}\text { Males } \\
N=246 \\
(\%)\end{array}$ & $\begin{array}{c}<65 \\
N=517 \\
(\%)\end{array}$ & $\begin{array}{c}\geq 65 \\
N=126 \\
(\%)\end{array}$ \\
\hline Single-site LBP & $101(16)$ & $52(13)$ & $49(20)^{a}$ & $69(13)$ & $32(25)^{\mathrm{b}}$ \\
\hline LBP (non-single-site) & $322(50 \%)$ & $199(50)$ & $123(50)$ & $275(53)$ & $47(37)^{\mathrm{b}}$ \\
\hline Total LBP (single and non-single site) & $423(66 \%)$ & $251(63)$ & $172(70)$ & $344(66)$ & $79(62)$ \\
\hline $\begin{array}{l}\text { Multi-site (four or more sites including } \\
\text { CWP) }\end{array}$ & $220(34)$ & $152(38)$ & $68(28)^{a}$ & $193(37)$ & $27(21)^{\mathrm{b}}$ \\
\hline
\end{tabular}

a Denotes statistical significance $(p<0.05)$ between males and females; ${ }^{b}$ denotes statistical significance $(p<0.05)$ between $<65$ and $>65$ years of age

(MED) per day and were considered high-opioid users (mean $=218 \mathrm{mg}$; range $=100-510 \mathrm{mg}$ ), while $83 \%$ were considered low-opioid users (mean $=30 \mathrm{mg}$; range $=2.25-90 \mathrm{mg} \mathrm{MED})$. Of the 28 patients receiving $>90 \mathrm{mg}$ MED, 13 exceeded $200 \mathrm{mg}$ MED (the "watchful dose" as per the 2010 Canadian Opioid guideline) [18].

In regard to general opioid use, more $\mathrm{CB}$ patients were using opioids than FB $(41 \%$ vs $31 \%)(p<0.01)$. There was no statistical difference in the proportions of patients using opioids in regard to sex $(M=39 \% ; F=35 \%)$ and diagnostic categories (group $\mathrm{I}=36 \%$, group $\mathrm{II}=39 \%$, group III $=33 \%)$. However, when data for high-opioid users were analysed with respect to country of birth, the proportion of $\mathrm{CB}$ patients taking $>90 \mathrm{mg}$ MED was found to be substantially higher than in FB patients. Specifically, while the CB:FB ratio was $1.3: 1$ for those using $<90 \mathrm{mg} \mathrm{MED}$, the ratio increased (in favour of CB) to 2.5:1 for those using $>90 \mathrm{mg}$ MED $(p<0.05)$, though the mean daily consumption for both types of groups of users (high-opioid users and low-opioid users) and ethnic backgrounds (CB and FB) was no different.

Current cannabis use was reported by $15 \%$ $(n=99)$ of the cohort (male 20\%; female 13\%), with a significant difference between $\mathrm{CB}$ and FB patients $(23 \%, n=83$ vs $6 \% ; n=16$ respectively; $p<0.01)$. When current cannabis use data were analysed based on diagnostic categories, group I reported less use $(11 \%, n=28)$, than groups II and III $(20 \%, n=54$ and $13 \%, n=13)$, respectively, though results were not statistically significant. Furthermore, $47 \%$ of patients had a medical prescription for cannabis for a licensed producer, $46 \%$ obtained cannabis from other sources, and $8 \%$ were using cannabis from both sources. Females were less likely than males to have a medical cannabis prescription (35\%, $n=18)$ vs $(46 \%, n=22$, see Fig. 2$)$. While pain was cited by $64 \%(n=63)$ as a reason for using cannabis, only $22 \%(n=22)$ used cannabis to treat the symptom of pain exclusively. Additional reasons for cannabis use were sleep disturbance $(41 \%)$, relief of anxiety/distress and relaxation (44\%), and to increase appetite $(12 \%)$. No statistically significant sex differences were found in reasons for cannabis use.

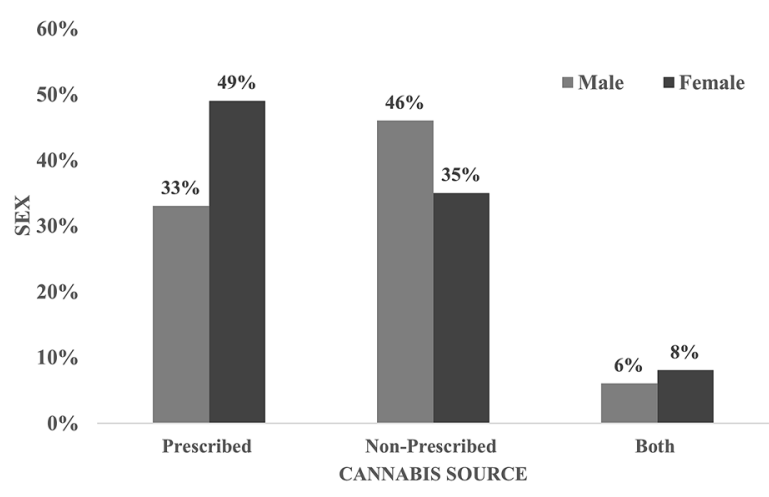

Fig. 2 Sex vs cannabis source. Women were more likely than men to have a medical cannabis prescription 


\section{DISCUSSION}

This Canadian study provides detailed information on the demographic and pain characteristics of 644 consecutive new patients attending PWC, an academic community-based pain clinic in the GTA. Our population consisted primarily of well-educated middle-age patients, often presenting with severe pain (in accordance with previous literature) [3] due to a car accident, disease or with spontaneous onset, with an average of seven or more years of pain duration. Forty-one percent had a primarily biomedical cause for their pain (group I), 43\% had mixed biomedical and psychological/psychosocial pathology (group II), and 16\% had evident psychopathology with no substantial detectable medical pathology (group III). Chronic widespread pain (CWP) was found in $11 \%$ of the entire cohort $(15 \%$ of females and $5 \%$ of males), and was twice as prevalent in patients younger than 65 years of age. Low back pain was present in $66 \%$ of the population, but was the sole site of pain in less than one third of patients with low back pain. Our data on singlevs non-single-site LBP is consistent with the published literature [19]. While opioids were used by one in three patients, the majority of users $(83 \%)$ were below $90 \mathrm{mg}$ of morphine equivalent with a mean daily consumption of $30 \mathrm{mg}$ morphine equivalent. Interestingly, our present data confirm the preponderance of Canadian-born patients between high-opioid users, similar to the observations we made several years earlier in a downtown Toronto population in an academic centre [10]. Notably, the presence of CWP (considered the result of central sensitization) [20] or non-anatomical sensory abnormalities (attributed to involvement of central nervous system maladaptive neuroplastic changes) [21] is associated with a poor prognosis for response to all therapeutic modalities (drugs, interventions, multimodal treatments, etc.) and return to gainful employment.

In an effort to understand patient characteristics and their relevance to treatment interventions, we attempted to compare our data to those obtained in a university-affiliated pain clinic in a Toronto tertiary-care hospital setting $[8,9]$, as well as a community-based clinic population (CHANGEpain) in British Columbia [12] and the Quebec registry data collected from five tertiary-care pain centres [11]. As data collection and batteries differed widely, only a few variables could be compared across the four different data sets. More comparable data were available from our previous study in a Toronto tertiary-care setting (Comprehensive Pain Program, or CPP) $[8,9]$. Data from the four cohorts are shown in Table 4 .

Interestingly, there was little variability across the four populations with respect to age, duration of pain, sex ratio or marital status. When it came to more comparable data between the PWC and CPP populations, similarities were demonstrated in regard to female preponderance, percentage of foreign-born, marital status and high opioid use, which was more prevalent in patients born in Canada than foreign-born patients. On the other hand, we found several differences between the PWC and CPP groups: the PWC cohort had a higher prevalence of older patients $(>65)$, patients with higher education, more likely to hold employment (full-time, part-time, self employed), and more likely to have biomedical pathology as the sole cause of pain. Opioid consumption differed as well between the groups in the sense that fewer PWC patients consumed opioids and in lower doses. The latter was attributable to a significant change in the climate of opioid use over the last decade (the CPP data were collected 13-16 years earlier), but did not change the fact that high opioid use is seen more frequently in Canadian-born patients. Some of these differences can be attributed to differences in populations, as the PWC is located in a large urban city north of Toronto serving primarily this city and several urban and rural areas above, while the CPP represented a mix of inner-core Toronto patients as well as patients throughout the province of Ontario.

We must stress that there are limitations in comparing populations across these four different data sets. The cohorts were all subject to substantial differences in settings, data collection, time of data collection, batteries used, 
Table 4 Comparative data from four pain cohorts

\begin{tabular}{|c|c|c|c|c|}
\hline & $\begin{array}{l}\text { PWC } \\
\text { Vaughan } \\
(644)\end{array}$ & $\begin{array}{l}\text { CPP } \\
\text { Toronto } \\
(1242)\end{array}$ & $\begin{array}{l}\text { CHANGEpain } \\
\text { Br. Columbia } \\
(933)\end{array}$ & $\begin{array}{l}\text { Quebec } \\
\text { Registry } \\
(6337)\end{array}$ \\
\hline Data collection period & $2016-2017$ & $2001-2004$ & $2016-2017$ & $2008-2013$ \\
\hline $\mathrm{F} / \mathrm{M}$ ratio & $1.6 / 1$ & $1.3 / 1$ & $2.3 / 1$ & $1.5 / 1$ \\
\hline Mean age & 50.4 & 48.5 & 49.5 & 52.8 \\
\hline Age $>65$ & $20 \%$ & $15 \%$ & - & - \\
\hline Education (college + university) & $60 \%$ & $46 \%$ & $82 \%$ & $54 \%$ \\
\hline Employment (FT, PT, self-employed) & $43 \%$ & $20 \%$ & $44 \%$ & $28 \%$ \\
\hline Married & $59 \%$ & $58 \%$ & $56 \%$ & $57 \%$ \\
\hline MVA & $28 \%$ & - & $35.7 \%$ & - \\
\hline \multicolumn{5}{|l|}{ Biomedical conditions } \\
\hline Nociceptive including MSK & $62 \%$ & $41 \%$ & - & - \\
\hline Neuropathic & $5 \%$ & $30 \%$ & - & $31 \%$ \\
\hline Mixed & $34 \%$ & $13 \%$ & - & $45 \%$ \\
\hline \multicolumn{5}{|l|}{ Diagnostic group categories } \\
\hline Group I & $41 \%$ & $26 \%$ & - & - \\
\hline Group II & $43 \%$ & $51 \%$ & - & - \\
\hline Group III & $16 \%$ & $21 \%$ & - & - \\
\hline \multicolumn{5}{|l|}{ CWP } \\
\hline Overall prevalence & $11 \%$ & $9 \%$ & - & $6.6 \%$ \\
\hline Group II prevalence $\mathrm{F} / \mathrm{M}$ & $17 / 4 \%$ & - & - & - \\
\hline Group III prevalence $\mathrm{F} / \mathrm{M}$ & $41 / 30 \%$ & $51 / 27 \%$ & - & - \\
\hline Pain duration (years) & $7 \pm 10$ & 8 years & $>5$ years $50.7 \%$ & $>5$ years $46.6 \%$ \\
\hline BPI pain interference score & $49 \pm 15$ & - & $44 \pm 14$ & - \\
\hline Severe pain intensity score & $59 \%$ & - & $34 \%$ & - \\
\hline$>1$ pain site & $74 \%$ & - & $51 \%$ & - \\
\hline Opioid users & $35 \%$ & $63 \%$ & $34 \%$ & - \\
\hline
\end{tabular}

analysis and regional variables. Several other factors relating to CNCP populations attending the above-described pain clinics could not be assessed, as patient referrals are often influenced by the expertise of a particular clinic, the needs of a given geographic area, distance from the clinic, physician training and specialization, preferences of both referring physicians and patients, availability and access to clinical services, length of waiting list and reimbursement considerations [22].

On the other hand, despite these limitations, we were able to deduce from the available data certain common characteristics between pain 
clinic populations, as well as substantial differences. We believe that understanding the population attending a particular clinic is of paramount importance for appropriate pain management. For example, older patients are more reluctant to take medications [23], something we have confirmed in the Toronto pain population we studied several years ago [9], and that we empirically confirm in our interactions with our present PWC population. Reluctance to take appropriate medications may pose a barrier to treatment for older patients with serious biomedical pain conditions, particularly when many other options are not feasible. The high proportion of PWC patients that cite car accident, slip-and-fall accident, or work-related injuries (39\% of our population) as the cause of pain includes involvement of the medicolegal system and compensation issues, and is relevant in our practice as it potentially reduces response to treatment. The literature indeed shows that such patients have inadequate response to traditional modalities when compared to pain patients not afflicted with compensatory injuries and may suggest benefits to alternative interventions [24].

The notion of patient phenotyping for chronic pain has already been adopted in the context of pain and clinical trials [25]. For example, clear sex and ethnic group differences have been demonstrated in response to multidisciplinary pain management programs $[26,27]$. In our own hands, phenotyping of our population provides us with treatment guidance. We have reported high rates of success in group II patients admitted to an intense customized interdisciplinary pain management program, both at the time of "graduation" from our program, and 6 and 12 months after program exit, with improvement ranging between 29 and $77 \%$ in different measures [28]. On the other hand, individuals who experience extensive biomedical pathology (group 1) have been successfully managed with medical interventions (manual therapy, medications, injections, surgery).

\section{CONCLUSION}

Our study demonstrates that CNCP patient populations present with varied phenotypes. Recognition of biomedical, psychological and socio-environmental factors affecting perception and expression of pain can promote better patient stratification and understanding of therapeutic needs. This approach can further provide economic benefits in a public health care system by appropriately rationing treatment interventions based on population characteristics and needs rather than simply on availability of service, to avoid the "one size (treatment) fits all" paradigm.

\section{ACKNOWLEDGEMENTS}

The authors would like to thank Alex Orlovic for his assistance during the data collection.

Funding. This research received no specific grant from any funding agency in the public, commercial or not-for profit sectors. No funding or sponsorship was received for the publication of this article.

Authorship. All named authors meet the International Committee of Medical Journal Editors (ICMJE) criteria for authorship for this article, take responsibility for the integrity of the work as a whole, and have given their approval for this version to be published.

Authors' Contributions. S.F.L., A. D., D.M., and A.M. contributed to the design and implementation of the research, to the analysis of the results and to the writing of the manuscript.

Disclosures. There are no financial relationships that might lead to a conflict of interest. Author Angela Mailis does not have any conflicts of interest regarding the publication of this paper. Author Amol Deshpande does not have any conflicts of interest regarding the publication of this paper. Author Demetry Assimakopoulos does not have any conflicts of interest regarding the publication of this paper. 
Author S. Fatima Lakha does not have any conflicts of interest regarding the publication of this paper.

Compliance with Ethics Guidelines. The study was approved by the University of Toronto, Research Ethics Board (Protocol\# 36903). Informed consent was obtained from all the patients attending the pain program (outlining the use of his or her data anonymously in aggregate format for research purposes).

Data Availability. Data will not be available in a public repository due to the patient privacy and confidentiality issue.

Open Access. This article is licensed under a Creative Commons Attribution-NonCommercial 4.0 International License, which permits any non-commercial use, sharing, adaptation, distribution and reproduction in any medium or format, as long as you give appropriate credit to the original author(s) and the source, provide a link to the Creative Commons licence, and indicate if changes were made. The images or other third party material in this article are included in the article's Creative Commons licence, unless indicated otherwise in a credit line to the material. If material is not included in the article's Creative Commons licence and your intended use is not permitted by statutory regulation or exceeds the permitted use, you will need to obtain permission directly from the copyright holder. To view a copy of this licence, visit http:// creativecommons.org/licenses/by-nc/4.0/.

\section{REFERENCES}

1. Nicholas M, Vlaeyen JW, Rief W, et al. The IASP classification of chronic pain for ICD-11: chronic primary pain. Pain. 2019;160(1):28-37.

2. Tauben D, Stacey BR. Evaluation of chronic noncancer pain in adults. Waltham: UpToDate, UpToDate, Inc.; 2020.

3. Schopflocher D, Taenzer P, Jovey R. The prevalence of chronic pain in Canada. Pain Res Manag. 2011;16(6):445-50.
4. Reitsma ML, Tranmer JE, Buchanan DM, Vandenkerkhof EG. The prevalence of chronic pain and pain-related interference in the Canadian population from 1994 to 2008. Chronic Dis Inj Can. 2011;31(4):157-64.

5. Steingrímsdóttir ÓA, Landmark T, Macfarlane GJ, Nielsen CS. Defining chronic pain in epidemiological studies: a systematic review and meta-analysis. Pain. 2017;158(11):2092-107.

6. Hogan ME, Taddio A, Katz J, Shah V, Krahn M. Incremental health care costs for chronic pain in Ontario, Canada: a population-based matched cohort study of adolescents and adults using administrative data. Pain. 2016;157(8):1626-33.

7. Canada Pain Fact Sheet, 2014 http://www. chronicpaintoronto.com/wp-content/uploads/ 2016/06/pain_fact_sheet_en.pdf. Accessed 25 Feb 2021.

8. Mailis-Gagnon A, Yegneswaran B, Lakha SF, et al. Pain characteristics and demographics of patients attending a university-affiliated pain clinic in Toronto, Ontario. Pain Res Manag. 2007;12(2):93-9.

9. Mailis-Gagnon A, Nicholson K, Yegneswaran B, Zurowski M. Pain characteristics of adults 65 years of age and older referred to a tertiary care pain clinic. Pain Res Manag. 2008;13(5):389-94.

10. Mailis-Gagnon A, Lakha SF, Ou T, et al. Chronic noncancer pain: characteristics of patients prescribed opioids by community physicians and referred to a tertiary pain clinic. Can Fam Physician. 2011;57(3):e97-105.

11. Choinière $\mathrm{M}$, Ware MA, Pagé MG, et al. Development and implementation of a registry of patients attending multidisciplinary pain treatment clinics: the Quebec Pain Registry. Pain Res Manag. 2017;2017:1-16.

12. May C, Brcic V, Lau B. Characteristics and complexity of chronic pain patients referred to a community-based multidisciplinary chronic pain clinic. Can J Pain. 2018;2(1):125-34.

13. Mailis A, Lakha SF. From (Ontario Ministry of Health and Long-Term Care) policy to implementation: a retrospective look at a community-based patient-centered model of care for chronic pain. Can J Pain. 2019;3(1):114-25.

14. Nelli JM, Nicholson K, Lakha SF, et al. Use of a modified Comprehensive Pain Evaluation Questionnaire: characteristics and functional status of patients on entry to a tertiary care pain clinic. Pain Res Manag. 2012;17(2):75-82. 
15. Lakha SF, Louffat AF, Nicholson K, Deshpande A, Mailis-Gagnon A. Characteristics of chronic noncancer pain patients assessed with the opioid risk tool in a Canadian tertiary care pain clinic. Pain Med. 2014;15(10):1743-9.

16. Angela M, Nivan Z, Maha A, Fatima Lakha S, Amol $D$, et al. Non Dermatomal Somatosensory Deficits (NDSDs) in chronic pain litigants. Chron Pain Manag. 2017;2017:J101.

17. Busse J, Guyatt G, Carrasco A, Akl E, Agoritsas T. The 2017 Canadian guideline for opioids for chronic non-cancer pain. Hamilton 2017.

18. Furlan AD, Reardon R, Weppler C. Opioids for chronic noncancer pain: a new Canadian practice guideline. CMAJ. 2010;182(9):923-30.

19. Hartvigsen J, Natvig B, Ferreira M. Is it all about a pain in the back? Best Pract Res Clin Rheumatol. 2013;27(5):613-23.

20. Banic B, Petersen-Felix S, Andersen OK, et al. Evidence for spinal cord hypersensitivity in chronic pain after whiplash injury and in fibromyalgia. Pain. 2004;107(1-2):7-15.

21. Mailis-Gagnon A, Giannoylis I, Downar J, Kwan CL, et al. Altered central somatosensory processing in chronic pain patients with "hysterical" anesthesia. Neurology. 2003;60(9):1501-7.

22. Lakha SF, Yegneswaran B, Furlan JC, Legnini V, Nicholson K, Mailis-Gagnon A. Referring patients with chronic noncancer pain to pain clinics: Survey of Ontario family physicians. Can Fam Physician. 2011;57(3):e106-12.

23. Rolnick SJ, Pawloski PA, Hedblom BD, Asche SE, Bruzek RJ. Patient characteristics associated with medication adherence. Clin Med Res. 2013;11(2): 54-65.

24. Littleton SM, Cameron ID, Poustie SJ, et al. The association of compensation on longer term health status for people with musculoskeletal injuries following road traffic crashes: emergency department inception cohort study. Injury. 2011;42(9):927-33.

25. Edwards RR, Dworkin RH, Turk DC, et al. Patient phenotyping in clinical trials of chronic pain treatments: IMMPACT recommendations. Pain. 2016;157(9):1851.

26. Pieh C, Altmeppen J, Neumeier S, Loew T, Angerer M, Lahmann C. Gender differences in outcomes of a multimodal pain management program. Pain. 2012;153(1):197-202.

27. Merry B, Edwards RR, Buenaver LF, McGuire L, Haythornthwaite JA, Doleys DM, Campbell CM. Ethnic group differences in the outcomes of multidisciplinary pain treatment. J musculoskelet Pain. 2011;19(1):24-30.

28. Mailis A, Robinson J, Lakha, Long Term Outcomes of Chronic Pain Patients Attending a Communitybased Interdisciplinary Pain (IDP) Program Funded by the Ontario Ministry of Health and Long Term Care (MOHLTC). Clinical innovation poster abstracts. Can J Pain. 2020;4(2):A1-21. https://doi. org/10.1080/24740527.2020.1765648. 